\title{
Professional qualification aimed at improving the customer
}

\author{
Gleiceanne Marques da Silva ${ }^{1}$, Maria da Conceição da Silva Tenorio ${ }^{1}$, Sônia de Andrade Terra ${ }^{1}$
}

${ }^{1}$ Laureate Internacional Universities (UNINORTE). Av. Joaquim Nabuco, No 1615. Manaus/AM. Brazil. CEP: 69020-030.

Email: gleiceannesilva@gmail.com, concy_tenorio@hotmail.com, soniaterra17@hotmail.com

Received: Agosto 29th, 2016

Accepted: October $14^{\text {th }}, 2016$

Published: December 22 ${ }^{\text {th }}, 2016$

Copyright $\odot 2016$ by authors and Institute of Technology Galileo of Amazon (ITEGAM) This work is licensed under the Creative Commons Attribution International License (CC BY 4.0).

http://creativecommons.org/licenses/by/4.0/ (c) (1) (2) (2) Open Actes:

\begin{abstract}
AABSTRACT
The service quality is a differentiator that the company should offer when the customer meets this quality require preparation, qualification of employees who must go through a learning period is required. The objective of this article is to deploy one (Training and Development) program T \& D for improving service to customers and employees. The methodologies and techniques were used through a case study conducted by a research field in City Radio Taxi company, through a questionnaire, interviews and direct observations. The results influenced the improvement of professional qualification, thus showing efficiency in the use of their service, fitness market with recovery and quality in customer service.
\end{abstract}

Keywords: Training; Development; Qualification; Quality; Customer and Client.

\section{Qualificação profissional visando a melhoria no atendimento ao cliente}

\section{RESUMO}

A qualidade no atendimento é um diferencial que a empresa deve oferecer quando atende o cliente, esta qualidade necessita de preparo, sendo necessária a qualificação dos colaboradores que devem passar por um período de aprendizagem. O objetivo do artigo é implantar um programa de T\&D (Treinamento e Desenvolvimento) para uma melhoria no atendimento aos clientes e colaboradores. As metodologias e técnicas utilizadas foram através de um estudo de caso realizado por uma pesquisa em campo na empresa Cidade Nova Radio Taxi, por meio de questionário, entrevistas e observações diretas. Os resultados obtidos influenciaram na melhoria da qualificação profissional, assim mostrando eficiência no aproveitamento do seu serviço, adequação no mercado com valorização e qualidade no serviço ao cliente.

Palavras Chaves: Treinamento; Desenvolvimento; Qualificação; Qualidade; Atendimento e Cliente.

\section{INTRODUÇÃO}

Em um mundo globalizado, tecnológico e competitivo, o mercado tem buscado colaboradores bem qualificados, por serem providos de conhecimento, tendo capacidade de rapidamente identificarem tarefas, expondo desenvoltura com os objetivos da empresa, com competência, agilidade e precisão.
As empresas para estabelecer contínuos conhecimentos, necessita desenvolver seus colaboradores, instituindo programa de treinamento, incentivando, motivando e deixando o mesmo bem articulado com os objetivos da organização, com tudo conforme [1], todos possuem um forte elo em comum: algo que confere competitividade a uma organização e é um fator que desempenha relevante influência dentre os componentes de uma fonte de vantagem competitiva. A empresa estabelecendo profissional 
qualificado contribui com a evolução da sociedade, expondo conjunta à qualidade no serviço, sendo de grande reconhecimento ao cliente. De acordo com [2], a qualidade é a filosofia de gestão que procura alcançar o pleno atendimento das necessidades e a máxima satisfação das expectativas dos clientes.

O profissional além de ser qualificado, carece de um treinamento adequado, sendo expedido a um processo de reintegração com a organização, fazendo que esteja à mercê de sua cultura organizacional, para desenvolver suas tarefas, compreendendo como realiza-las e adquirindo conhecimento continuo junto à empresa, afirma [3] .

Os empregados devem refletir seriamente sobre o conhecimento de sua empresa. Colaborados bem qualificados, tem excelente capacidade para desempenhar suas funções junto à empresa, com finalidade de prestar excelência em atendimento no serviço aos clientes, atendendo as suas expectativas, assim o colaborador traz a organização satisfatórios resultados, com isso [4], Para um bom atendimento, há alguns pré-requisitos e o desafio da linha de frente é proporcionar um bom serviço técnico, além de transmitir atenção e simpatia.

A qualidade é um diferencial que a empresa deve oferecer ao cliente, pois como [5], a satisfação do cliente com a qualidade do serviço pode ser definida pela comparação da percepção do serviço prestado com as expectativas do serviço desejado.

Para que essa problemática venha a ser solucionada, é necessária implantação do programa T\&D (Treinamento e Desenvolvimento), fazendo que o colaborador consiga desenvolver seu trabalho na organização com clareza, objetividade e determinação, em contrapartida vai melhorar o atendimento ao cliente. Assim tem-se como objetivo aperfeiçoar os colaboradores, mostrando que o T\&D resultara em conhecimento elevado no alcance dos objetivos da organização, em suas tarefas, qualidade em seu desempenho, melhorando o atendimento aos seus respectivos clientes, provindo crescimento tanto do profissional, quanto da organização que amplia o número de clientes fiéis aos serviços prestados.

\section{REVISÃO BIBLIOGRÁFICA}

A qualificação do profissional é direcionada a função do trabalho que por meio do conhecimento, competência, habilidades, técnicas e capacidade do indivíduo, se é capaz de distinguir como ele vai ser capacitado para assumir um cargo junto à organização. Portanto [6] a qualificação profissional é um termo polissêmico, que é fruto do processo de produção material da vida, logo passível de embates e divergências quanto a sua apropriação. Neste método de qualificação profissional, não se deve atribuir exclusividade as técnicas do indivíduo, mas a maneira de realizar as tarefas atribuídas, educação no âmbito das tarefas, formando um conjunto de conhecimentos que vai da prática a teoria.

Assim conforme [7], a qualificação, mais do que o aprendizado de um conjunto das rotinas vinculadas a um posto de trabalho, centrada no saber-fazer, implica por ser relação e construção social - complexa, contraditória e multideterminada a percepção ampla de seus objetivos, conteúdos e métodos, o que incluiria, por exemplo, a dimensão social do trabalho, a autonomia do trabalhador e as qualificações táticas, construídas no cotidiano do trabalho.

\section{II.1. TREINAMENTO E DESENVOLVIMENTO}

No momento que um colaborador se orgulha de seu trabalho, fazendo com melhor desenvoltura, se recebe um resultado eficaz para a empresa, e para isso se necessita de diversas cognitivas, o T\&D é uma grande estratégia que auxilia em uma qualidade elevada das tarefas dos colaboradores da empresa, pois é uma ferramenta que aglutina valor à organização, desenvolvendo pessoas para melhor capacitação de suas tarefas, assim as motivando.

Segundo [8], o T\&D é uma forma de a empresa reconhecer o valor das pessoas, na medida em que demostra interesse e investir nelas. Em segundo lugar, o T\&D também representa um desafio e uma saudável quebra na rotina. Por fim, os programas de T\&D podem estar articulados a outras iniciativas, como o estabelecimento de metas ou planos de recompensas, contribuindo, assim, para integrar as estratégias de motivação e retenção.

As empresas para melhor atender seus clientes, estão buscando a qualificação dos colaboradores. Assim, o T\&D traz a organização uma forma adequada de adapta-lo no seu ramo de trabalho, fazendo que o mesmo seja treinado, melhorando o aproveitamento de suas tarefas e lhe acrescentando conhecimento continuo. Neste sentido expõe [9] o treinamento e o desenvolvimento - juntamente com a função buscar e recolher os melhores profissionais para a empresa - encabeçam a área de recursos humanos que deve se preocupar em treinar os funcionários para o exercício de suas tarefas.

\section{II.1.1. TREINAMENTO}

O treinamento é um estudo comportamental, desempenhando o colaborador junto a realização de tarefas, enfatizando melhor forma a realiza-la no ambiente de trabalho, desenvolvendo a idoneidade para sumo aproveitamento de sua capacidade profissional.

Portanto [10], treinamento consiste em um processo educacional que é aplicado de maneira sistémica e organizada e pelo qual as pessoas adquirem conhecimentos, atitudes e habilidades em função de objetivos definidos.

$\mathrm{Na}$ obtenção de resultados, o treinamento tem finalidade de aprimoramento do serviço prestado à organização, sendo relevante um processo estirpe, mostrando ao colaborador avença a realização de tarefas, adquirindo conhecimento pela mesma, assim a empresa realiza excelente qualidade na desenvoltura dos colaboradores.

Portanto [11], treinamento é o processo de assimilação cultural a curto prazo, que objetiva repassar ou reciclar conhecimento, habilidades ou atitudes relacionadas diretamente à execução de tarefas ou à sua otimização no trabalho.

\section{II.1.2. DESENVOLVIMENTO}

O desenvolvimento é um assunto complexo que faz parte do agrupamento de experiência e oportunidades de conhecimento simétrico pela empresa, possibilitando a evolução pessoal do colaborador, o incentivando, motivando e agregando valor ao mesmo, para ser capaz de aprender e gerar sapiência. Assim conforme [12] o desenvolvimento possui foco na carreira das pessoas, nos cargos que deverão ser ocupados por elas nas organizações, desenvolvendo, a partir daí as habilidades, agilidades e aptidões que o novo cargo exigirá.

O desenvolvimento vem da capacidade do indivíduo junto a empresa em aprender, ter conhecimento do que é proposto, obtido através do treinamento, adquirindo novas habilidades, conhecimento e transformação de comportamento e atitudes. Portanto, [13] o desenvolvimento aborda atividades cuja finalidade 
é fomentar o conhecimento e o crescimento pessoas e profissional do funcionário, a fim de que este atue na empresa com maior motivação e tenha um desempenho melhor em suas atividades.

\section{II.2. SATISFAÇÃO DO CLIENTE}

O cliente na busca de um produto ou serviço faz comparação entre diversas empresas, com a intenção de obter uma, sendo fiel pelo fato do atendido adequado motivado pelos colaboradores, e a organização atender suas perspectivas, podendo ser um processo extenso até chegar à satisfação. Explica [14], dizem que "os clientes experimentam vários níveis de satisfação ou de descontentamento após cada experiência de serviço de acordo com a medida na qual suas expectativas foram atendidas ou ultrapassadas".

A satisfação vem além do produto, é o laço entre produto e atendimento, sendo ou não agradado ao cliente, deve ter qualidade, atendendo as necessidades dos compradores, podendo sofrer modificações por se adequar constantemente as mudanças no mercado, para chamar atenção dos seus possíveis compradores ou usufruidores dos serviços ou produtos.

Assim [15] relata que satisfação consiste na relação de prazer ou desapontamento resultante na comparação do desempenho (ou resultado) percebido de um produto em relação às expectativas do comprador.

\section{PROCEDIMENTOS METODOLÓGICOS}

Neste contexto o método utilizado foi o dedutivo por evidenciar acontecimentos verídicos por meio de teorias, livros e artigos com um levantamento real, em um conjunto de ações à identificação de um determinado problema, consistindo em verificar e estudar atiladamente com desfecho apropriado à obtenção de resultado, conforme [16].

$\mathrm{O}$ raciocínio dedutivo tem o objetivo de explicar o conteúdo das premissas. Por intermédio de uma cadeia de raciocínio em ordem descendente, de análise do geral para o particular chega-se a uma conclusão.

A pesquisa consiste em estudo de caso referente ao treinamento e desenvolvimento dos colaboradores da Associação Cidade Nova Rádio Táxi por intermédio de averiguação detalhada por meio da técnica qualitativa, assim [17] ressalta que pesquisa é o conjunto de procedimentos sistemáticos, baseado no raciocínio lógico, que tem por objetivo encontrar soluções para problemas propostos, mediante a utilização de métodos científicos. A pesquisa foi realizada por meio de entrevistas, questionários, e prévias visitas à organização, se obtendo avaliações ao seu meio, em seguida houve um estudo em referenciais teóricos para melhor entendimento do problema e sua resolução.

Tendo o treinamento e desenvolvimento como principal problema, assim visualizando a forma que a empresa realiza o recrutamento e seleção para seus possíveis colaboradores, tendo em vista diversos métodos, objetivando a solução de problemas atrelados a uma qualificação conforme as técnicas e competências do indivíduo, coagindo a um treinamento propício, desenvolvendo o colaborador as suas atividades junto à organização.

\section{ESTUDO DE CASO PROPOSTO}

A Associação Cidade Nova Rádio Táxi foi fundada em 23 de junho de 1989, com mais de 20 anos de experiência, prestando serviço de transporte individual de passageiros, certificada pela INBRAP (Instituto Brasileiro de Pesquisa De Opinião Pública).

A Associação Cidade Nova Radio Taxi trabalha no segmento de transporte seletivo de passageiros, encomendas e malotes, possuindo uma frota de táxi com 178 carros do tipo executivo e peruas, todos com ar-condicionado, dispondo colaboradores fardados e munidos de identificação, 18 pontos de apoio distribuídos estrategicamente pela cidade de Manaus.

A empresa possui um quadro funcional de 210 colaboradores, sendo 13 do sexo feminino e 197 do masculino, os quais desempenham funções em áreas diferenciadas, com faixas etárias conforme a Figura 1, composto por presidente, vicepresidente, secretário, atendentes e recepcionista de acordo com a Figura 2, desta forma entende-se que é uma empresa de grande porte.

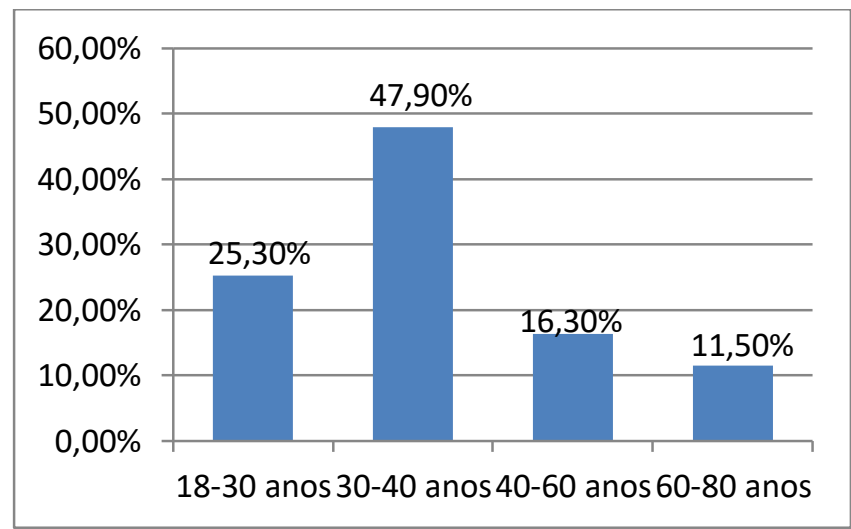

Figura 1: Faixa etária dos funcionários.

Fonte: Autores, (2016).

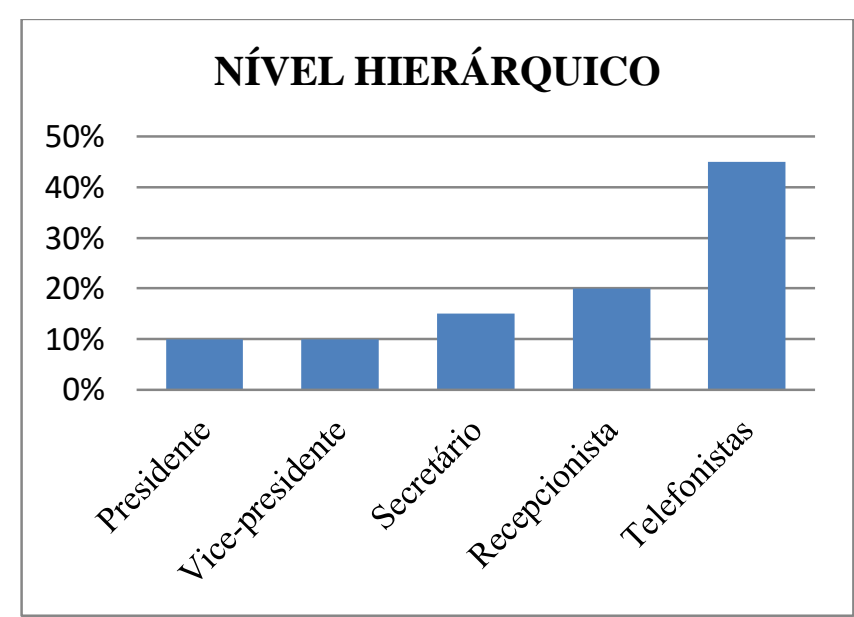

Figura 2: Distribuição dos colaboradores.

Fonte: Autores, (2016).

A estrutura da empresa está localizada em uma área que corresponde a $800 \mathrm{~m}^{2}$ com as seguintes repartições, com salas do presidente, operador de rádio e de telefonistas divididas em baias.

O layout da empresa está de acordo com o estabelecido pelos especialistas em Estrutura Organizacional, visto que o ambiente se encontra de forma otimizada, de fácil acesso e locomoção dos colaboradores.

A organização dispõe como fornecedor a MOURA, disponibilizando equipamentos para manutenção dos carros como pneus, baterias, óleos, entre outros utensílios relacionados aos carros. Em tecnologia, a associação dispõe de equipamentos como 
uma torre de comunicação de 30 metros de altura na parte externa, sala com um gerador dando suporte caso haja queda de energia, uma CPU de armazenamento de dados, sala de operadores, sistema de internet banda larga nos departamentos de operação central de filmagem, distribuídos com 13 câmeras monitorando todos os departamentos interno e o ambiente externo.

\section{IV.1 ANÁLISE DO PONTO CRÍTICO}

A análise é feita pelo gráfico radar apresentado na Figura 3, que evidencia a avaliação das áreas internas da organização.

Conforme [18] o gráfico radar "é uma forma clara e pictórica de representar o resultado da análise de cada uma das 10 áreas mencionadas, trata se de um gráfico construído de forma circular, espalhando-se, de forma radial".

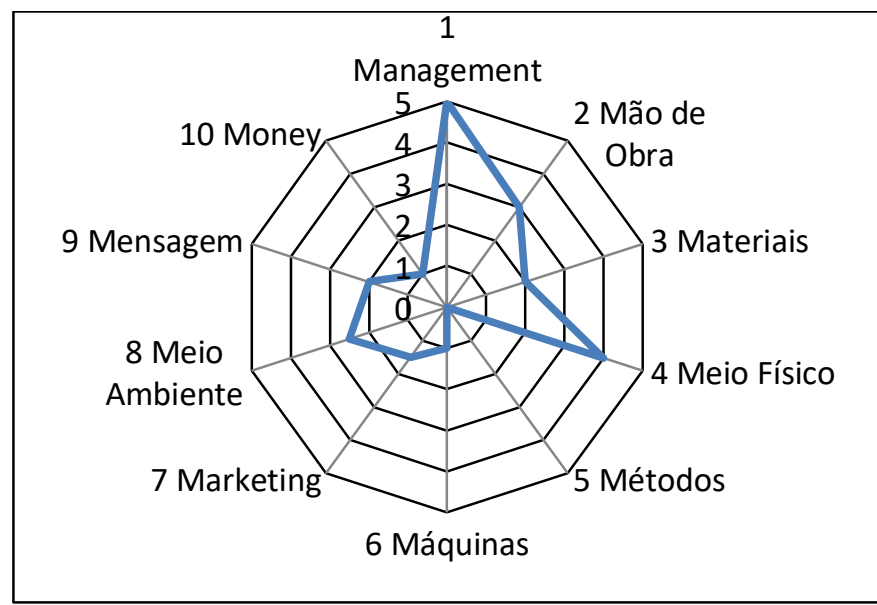

Figura 3: Gráfico das Áreas Críticas.

Fonte: Autores, (2016).

Portanto se nota que o Management posicionado na Zona 5 se encontra com profunda necessidade de aperfeiçoamento, pela empresa reter um processo ineficaz de seus colaboradores no desenvolvimento da organização, pois os mesmos não estão providos de conhecimento sobre as áreas submetidas, realizando com incoerência ou mesmo desídia.

Por ser a área de estrema importância, onde os colaboradores desempenham função para o crescimento da organização, tem como preliminar o recrutamento apropriado com uma seleção eficaz conforme a qualificação, sendo por imprescindível a implantação de um T\&D Treinamento e Desenvolvimento de seus colaboradores para elevado proveito dos cargos a provir.

\section{IV.2. QUALIFICAÇÃO DOS COLABORADORES}

A qualificação é um procedimento que deve ser tomado com muita cautela, posicionando o indivíduo as suas funções na empresa, munidos de conhecimentos e competência ao tomar decisões e exercer suas atividades com atitude e habilidade. Conforme pesquisado na Associação Cidade Nova Rádio Táxi, os associados que estão na parte externa da organização e exercem profissão de motorista, estão munidos apenas de carteira de habilitação e os profissionais da área interna onde constituem as telefonistas, secretária e o operador de rádio não apresentam estudo aprimorado, técnicas e habilidades, com árduo nível educacional.

Apresentado esta problemática, propõe-se a organização realizar uma qualificação com mais apreço nas técnicas e conhecimento especifico nas áreas de seus colaboradores provendo formação adequada, capacitação e cursos técnicos, desta forma, um profissional bem qualificado obterá sumo rendimento a empresa.

\section{IV.3. TREINAMENTO DE DESENVOLVIMENTO DOS COLABORADORES}

A empresa estudada não possui um setor de treinamento e desenvolvimento de seus colaboradores, presumindo, portanto que os funcionários mais antigos são os responsáveis pelos ensinamentos dos novos profissionais através do compartilhamento de suas experiências. Os colaboradores com este processo, não estabeleciam proveito das suas atividades, pelo desinteresse da organização por não apresentar deferência aos indivíduos, resultando exígua permanência do colaborador na organização.

$\mathrm{O}$ treinamento faz parte de um amplo conhecimento das tarefas do colaborador, sendo de estudo continuo adequando-os de acordo com as mudanças globais, aglutinando adequadas formas de realizar tarefas com competência, habilidade intelectual, técnica, atitude e conhecimento estirpe à organização.

A empresa para estabelecer cuidadosamente este processo, além de ser continuo, necessita motivar seus colaboradores a crescerem, elaborando eles a satisfação de suas tarefas, [19] ressalta que treinamento não é algo que se faça uma vez para novos empregados: é usado continuamente nas organizações bem administradas.

Assim como num jogo, em que os jogadores no momento do intervalo, estão sendo orientados pelo treinador para descobrir suas falhas, e sendo adequados para agirem corretamente no campo. Também é na empresa, em que os colaboradores devem estar bem localizados num processo de busca pela melhor forma de realizar suas atividades dentro da organização, treinando sua capacidade, habilidade, e adquirindo um conhecimento continuo.

A Associação Cidade Nova Rádio Táxi ao verificar com apreço esta problemática junto ao gestor dos recursos humanos, realizou um treinamento na parte interna da organização com as atendentes e recepcionistas para uma adequação na comunicação com os clientes de modo mais informal, tendo habilidades e atitudes necessárias para um sensato aperfeiçoamento de seus postos na organização, aglutinando as necessidades do cliente com determinado apresso.

No ambiente externo, a organização está disposta a aprimorar o tempo de entrega do serviço e solicitar cursos técnicos de linguagem, aglutinando a um estudo aprimorado na comunicação e relacionamento com os clientes da região e possíveis estrangeiros. O objetivo deste respectivo treinamento é conduzir a empresa para as exigências do mercado, fortalecendo o negócio, diminuindo então o tempo de espera do cliente ao adquirir o serviço.

\section{IV.4. NÍVEL DE ATENDIMENTO E SATISFAÇÃO DOS CLIENTES}

$\mathrm{Na}$ pesquisa foi constatado que a empresa realiza o monitoramento do nível de satisfação em relação ao atendimento dos clientes, sendo um processo continuo, assim, de acordo com a pesquisa realizada se estabeleceu um resultado mediano como mostra a Figura 4. Vale ressaltar que o nível de atendimento aos clientes é de estrema importância, sendo atrelado a uma fidelização ao produto ou serviço oferecido, o atendimento deve ser feito com atenção, introduzindo claramente e com agilidade as informações com conhecimento adequado. A satisfação do cliente em relação 
ao serviço oferecido requer um conhecimento da organização que deve ter consciência se o produto ou serviço está sendo apreciado pelo seu público alvo.

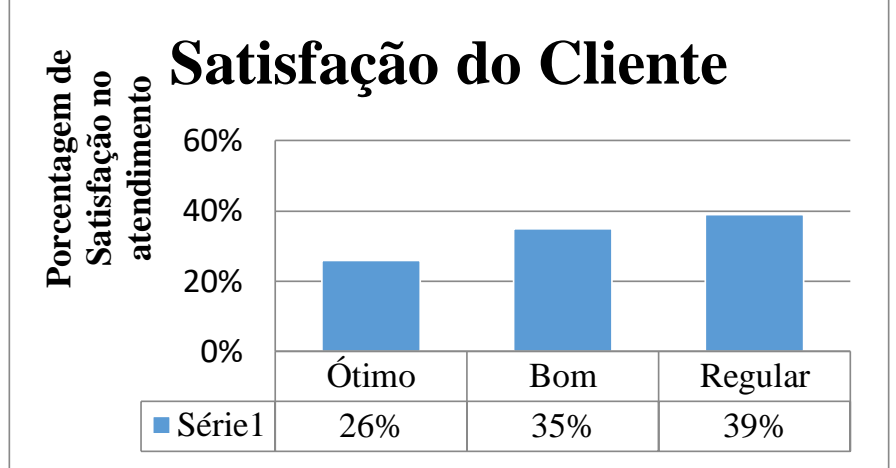

Figura 4: Índice de satisfação dos clientes em relação ao serviço prestado pela empresa.

Fonte: Autores, (2016).

Com estes resultados, foi oferecida a associação uma forma mais satisfatória, fazendo a organização investir mais em tecnologia, qualidade na comunicação sendo de cunho informal, continuação no processo de relatórios de satisfação mostrado anteriormente e bonificações aos fiéis clientes.

\section{V.CONCLUSÕES}

Diante do estudo exposto, chagamos ao entendimento de que é imprescindível um profissional bem qualificado para ocupar um cargo na empresa, devendo estar aglutinado a um treinamento adequando suas habilidades e capaz de realizar as tarefas com excelência e desenvoltura. Também é necessário o desenvolvimento do colaborador para aferir os objetivos da organização, obtendo desta forma, a satisfação ao exercer suas atividades. Portanto o colaborador deve conhecer bem a organização, com conhecimento e informações às suas mudanças, sendo relevante um processo propenso para melhor atender seus objetivos, percorrendo ao melhor atendimento de seus clientes por se tratar de um ponto importante no progresso da empresa, onde se estabelece fieis clientes com atendimento harmonioso e dedicado, visto que um serviço bem repassado gera um cliente satisfeito.

\section{AGRADECIMENTOS}

Ao Centro Universitário do Norte (UNINORTE) e Associação Cidade Nova Rádio Táxi pelo apoio a realização desta pesquisa.

\section{REFERÊNCIAS}

[1] GODOY, Arilda Schmidt et al. Gestão do Fator Humano: Uma visão Baseada em Stakeholders. $2^{\circ}$ ed. São Paulo: Saraiva, 2008, p.218.

[2] LACERDA, Flávia Alves de Brito. Gestão da qualidade: Fundamentos da Excelência. Brasilia: Sebrae, 2005, p.50.

[3] FAYARD, Pierre. O inovador modelo japonês de gestão do conhecimento. Porto Alegre: Bookman, 2010, p.112.

[4] LAS CASAS, Alexandre Luzzi. Administração de marketing: conceitos, planejamento e aplicações à realidade brasileira. 1. ed. São Paulo: Atlas, 2012. 528 p.
[5] FITZSIMMONS, James A; FITZSIMMONS, Mona J. Administração de Serviços - Operações, estratégia e tecnologia da informação. 6. Ed. Porto Alegre: Bookman, 2010, p. 139.

[6] OLIVEIRA, Rafael Bastos Costa. A proposta de qualificação profissional do Reuni: Contradições e possibilidades. Portal Domínio Público, Rio de Janeiro, 2010. Dsponível em: <http://www.dominiopublico.gov.br/pesquisa/DetalheObraForm.d o? select_action=\&co_obra=199963>. Acesso em: 16/04/2014 às 22:00.

[7] LIMA, A. A. A qualificação no sistema público de emprego: uma análise a partor das resoluções do CODEFAT. In: Oliveira, Roberto Véras (org.). Políticas Públicas de Qualificação: Desafios Atuais. São Paulo: A Comunicação, 2007, p.63.

[8] VIZIOLI, Miguel. Administração de Recursos Humanos. São Paulo: Pearson Education do Brasil, 2010, p.148.

[9] RIBEIRO, Antônio de Lima. Gestão de Pessoas. São Paulo: Saraiva, 2005.

[10].CHIAVENATO, Idalberto. Treinamento e Desenvolvimento de recursos humanos: como incrementar talentos na empresa. $7^{\circ}$ ed. São Paulo: Manoele, 2009, p.41.

[11] MARRAS, Jean Pierre. Administração de recursos humanos: do operacional ao estratégico. $3^{\circ}$ ed. São Paulo: Futura, 2000, p.145.

[12] BOTELHO, Joacy Machado; BRUNO, César Scaramuzza. Treinamento e Desenvolvimento em Recursos Humanos. Convibra administração, Paraná, 2012. Disponível em: $<$ http://www.convibra

.com.br/artigo.asp?ev=25\&p=\&lang=pt\&id=50 48>. Acesso em: 16/04/2014 às 07:18.

[13] BENOSSI, Gardênia. Gestão do conhecimento no treinamento e desenvolvimento de pessoas. Biblioteca Digital, Campinas, 2009. Disponível em: <http://www.bibliotecadigital.puccampinas.edu .br/tde_busca/arquivo.php?codArquivo $=501>$. Acesso em: 19/04/2014 às 10:08.

[14] LOVELOCK, Christopher; WRIGHT, Lauren. Serviços: marketing e gestão. São Paulo: Saraiva, 2004, p.113.

[15] KOTLER, P; ARMSTRONG, G. Administração de marketing. 12 ed. São Paulo: Pearson Prentice Hall, 2007, p.58

[16] MARQUES, Dorli J. C. Trabalhos acadêmicos: normas e fundamentos. Manaus: Faculdade Salesiana Dom Bosco, Universidade Federal do Amazonas, 2006, p.77.

[17] ANDRADE, Maria Margarida. Introdução à metodologia do trabalho científico. $10^{\circ}$ ed. São Paulo: Atlas, 2010, p.109.

[18] COSTA, Eliezer Arantes. Gestão Estratégica: da empresa que temos para a empresa que queremos. 2 ed. São Paulo: Saraiva, 2007, p.118.

[19] LACOMBE, Francisco José Massef. Recursos Humanos: Princípios e Tendências. $2^{\circ}$ ed. São Paulo: Saraiva, 2011, p.379. 